\title{
Assessment of Borrelia miyamotoi in febrile patients and ticks in Alsace, an endemic area for Lyme borreliosis in France
}

Pierre H. Boyer ${ }^{1}$, Joris Koetsveld², Laurence Zilliox ${ }^{3}$, Hein Sprong ${ }^{4}$, Émilie Talagrand-Reboul ${ }^{1}$, Yves Hansmann ${ }^{1,5}$, Sylvie Josiane de Martino ${ }^{1,3}$, Nathalie Boulanger ${ }^{1,3}$, Joppe W. Hovius ${ }^{2}$ and Benoît Jaulhac ${ }^{1,3^{*}}$

\begin{abstract}
Background: Borrelia miyamotoi is a relapsing fever Borrelia species transmitted by ticks of the Ixodes ricinus complex. Human disease caused by B. miyamotoi was first described in Russia and later in the USA and Japan. Additionally, five cases of meningoencephalitis in immunocompromised patients and one case in an apparently immunocompetent patient were described.

Methods: We investigated the presence of B. miyamotoi in I. ricinus nymphs and in patients suspected of human granulocytic anaplasmosis, in Alsace (France), an endemic area for I. ricinus ticks and Lyme borreliosis, using direct (PCR) and indirect diagnosis (glycerophosphoryldiester-phosphodiesterase (GlpQ) serology).

Results: Borrelia miyamotoi was found in 2.2\% of 4354 ticks collected between 2013 and 2016. None of the 575 blood samples, collected from the patients suspected of HGA, was found positive for B. miyamotoi by PCR. Acute and late sera from 138 of these 575 patients were available. These paired sera were tested for IgM and IgG antibodies against the B. miyamotoi GlpQ antigen. A total of 14 out of 138 patients had at least one positive parameter (i.e. anti-GlpQ IgG and/or $\lg M$ ). One patient seroconverted for $\lg G$, and three had isolated $\lg M$ in the acute serum. These three patients were treated with doxycycline which could have prevented seroconversion. After reviewing clinical data and other biological tests performed, co-exposure among different microorganisms vectored by ticks or serological cross-reactivity could not be ruled out in these different cases. One patient had persistent lgG, which strongly suggests previous exposure to B. miyamotoi.
\end{abstract}

Conclusions: Humans can be exposed to B. miyamotoi through tick bites in Alsace. We present serological data for possible $B$. miyamotoi exposure or infection of patients with fever after tick bite. Future studies should determine the incidence, clinical course and burden of this emerging tick-borne disease in other parts of Western Europe.

Keywords: Borrelia miyamotoi, Borrelia miyamotoi disease, GlpQ, Tick-borne diseases, Post-tick bite fever

\section{Background}

Borrelia miyamotoi is currently the only Borrelia species belonging to the relapsing fever group that is transmitted by ticks of the Ixodes ricinus complex [1]. In 2011,

\footnotetext{
*Correspondence: jaulhac@unistra.fr

${ }^{1}$ University of Strasbourg, Virulence bactérienne précoce UR7290-Lyme borreliosis group, FMTS - CHRU Strasbourg, Institut de Bactériologie, Strasbourg, France

Full list of author information is available at the end of the article
}

the first series of patients with febrile diseases caused by B. miyamotoi were described in Russia [2] and later in the USA [3-5]. The disease was designated as Borrelia miyamotoi disease (BMD) or hard tick-borne relapsing fever and should be the object of differential diagnosis of human granulocytic anaplasmosis (HGA) [3]. In parallel, cases of meningoencephalitis caused by $B$. miyamotoi in highly immunocompromised patients, receiving B-cell depleting therapy have been described since 2013 and 
one case was reported in an apparently immunocompetent patient [6-9]. In central Europe, only one blood sample has been found to be PCR-positive so far, albeit in a person without symptoms [10]. However, serological evidence for exposure was found among forestry workers [11]. More recently, a case of post-tick bite febrile syndrome has been reported in western Europe, and serological results suggested that $B$. miyamoto $i$ was the causative agent of the patient's symptoms [12].

The Alsace region of France is an area with a high density of I. ricinus [13-15]. Since B. miyamotoi was found in I. ricinus ticks in France and surrounding countries [16-18], we aimed to study the prevalence of B. miyamoto $i$ in patients suspected of post-tick bite febrile illness in northeastern France using direct and indirect diagnostic tools, as well as by measuring $B$. miyamotoi infection rates in $I$. ricinus ticks collected in the same region.

\section{Methods}

\section{Study area and tick collection}

Alsace is a region located in the northeastern part of France, bordering Germany. Four collection sites were investigated in different locations in the region, with variable vegetation and environment (i.e. natural or suburban). These sites were defined in previous studies [13, 19], and details are shown in Additional file 1: Table S1. Among these four sites, site A was defined as the control site because of the low prevalence of Lyme borreliosis in this area $[13,19]$.

From April 2013 to November 2016, 4354 questing I. ricinus nymphs were field collected by dragging a white flannel flag $(1 \times 1 \mathrm{~m})$ over low vegetation.

\section{Patients and whole blood samples}

Between May 2010 and July 2016, EDTA blood samples from 575 patients were sent to the clinical microbiology laboratory of the University Hospitals of Strasbourg for Anaplasma phagocytophilum diagnosis by PCR. From May 2010 to July 2012, these patients were recruited for the study of HGA [20]. The inclusion criteria were (i) fever or another symptom presumed to be related to a tick bite occurring within a maximum of 4 weeks before the beginning of symptoms; (ii) patients exposed to tick bites with fever and at least one haematological abnormality or abnormal liver function tests; and (iii) patients with at least one haematological abnormality or abnormal liver function tests occurring maximum 4 weeks after a proven tick bite. At the time of recruitment, patients were examined by infectious disease specialists, and an aetiological investigation was thoroughly conducted to establish a differential diagnosis. Clinical data at the time of examination were obtained by a standardized questionnaire.
For the period from July 2012 to July 2016, all the blood samples sent to Strasbourg University laboratory for investigation of $A$. phagocytophilum by PCR were examined. They were issued from the same hospitals as in the previous period, but clinical data were not obtained.

\section{Serum samples}

For a subset of 138 of the 575 patients presented above, both acute and convalescence sera were available. Serum samples were obtained at the same time as the EDTA whole blood samples for PCR. Additionally, 50 healthy blood donors from Alsace and 50 donors from a nonendemic region for Lyme borreliosis, were used as negative controls to determine the serological background in the French population.

Blood samples stored at $-80{ }^{\circ} \mathrm{C}$ and serum samples stored at $-30{ }^{\circ} \mathrm{C}$ were retrospectively analysed by realtime PCR and serology respectively.

\section{Pan-relapsing fever Borrelia PCR}

Detection of relapsing fever (RF) Borrelia was performed by real-time PCR adapted from a protocol published by Hovius et al. [6] targeting a 200-bp fragment of the $16 \mathrm{~S}$ rDNA. Each positive sample was sequenced by the GATC Biotech company (Mulhouse, France) using the Sanger method with the primers F-relfev and R-relfev.

Bacterial identification was performed using bacterial phylogenic analysis with the Bioinformatics Bacterial Identification tool (leBIBI $\left.{ }^{\mathrm{QBPP}}\right)$ [21].

As a confirmation assay, a second B. miyamotoi realtime PCR test, targeting a 116-bp fragment of the flagellin gene of B. miyamotoi, was performed on a subset of 135 nymphs [6].

\section{Borrelia miyamotoi GlpQ serology}

Serum reactivity against recombinant GlpQ was tested for IgM and IgG antibodies with an ELISA technique as previously described [22, 23]. The cut-off values were calculated as the mean result plus three times the standard deviation of the 10 negative controls included in each experiment. All the sera were tested twice in separate experiments. Positive sera were subsequently tested by western blot as previously described [22]. IgG and IgM serology was considered as positive when both ELISA and western blot were deemed positive.

\section{BMD case definition}

BMD cases were divided upfront into three categories according to the level of evidence of the technique used (i.e. molecular biology or serology). Cases proven by both 
PCR methods were defined as confirmed cases. Serological results were interpreted according to the delay between the onset of the symptoms and the sampling of the serum. Contact with B. miyamotoi was considered as probable in patients who seroconverted whatever the result of the anti-GlpQ IgM in the acute serum. Exposure to $B$. miyamotoi was considered as possible in patients with solitary IgM in sera obtained within 11-20 days after the onset of the symptoms (a compatible delay for the only appearance of anti-GlpQ IgM antibodies) [22] and treated with doxycycline, which could abort seroconversion [24]. Solitary IgM or persistent IgM positivity was classified as false IgM results, when there was evidence of an infection with other microorganisms (e.g. cytomegalovirus or Epstein-Barr virus) which are known to give a polyclonal response in serological assays. Finally, patients with persistent IgG were considered as previously exposed to B. miyamotoi.

\section{Statistical analysis}

Ticks infection rates were calculated and expressed as percentages with their $95 \%$ confidence interval. Statistical modelling using a generalized linear model was performed to assess B. miyamotoi prevalence in ticks in these four different locations. Data were analysed using R Studio R version 3.4.0 (2017-04-21, https://cran.r-project.org/).

\section{Results and discussion}

Borrelia miyamotoi vector epidemiology in Alsace

All the 4354 nymphs collected during the years of field sampling were morphologically identified as I. ricinus nymphs. Among these 4354 nymphs, 2.18\% (95\% CI: 1.77-2.67) $(\mathrm{n}=94)$ were positive by pan-RF Borrelia PCR. Amplicon sequences obtained by the 165 rDNA PCR assay allowed the identification of B. miyamotoi, and no other RF Borrelia species was identified. The $B$. miyamotoi-specific confirmatory PCR assay performed on a subset of 135 nymphs was $100 \%$ consistent with the identification obtained by the $16 \mathrm{~S}$ rDNA PCR. Thirteen nymphs were positive and 122 were negative according to both techniques, which indicates neither a lack of sensitivity nor lack of specificity.

The generalized linear model revealed a disparity in $B$. miyamotoi prevalence in $I$. ricinus ticks among the four collection sites (Additional file 1: Table S1). Indeed, the odds ratio of $B$. miyamotoi infection rate was significantly higher in site B (OR: 2.718, 95\% CI: 1.218-6.069) than for the control site A. The detailed prevalence rates over four years and on the four collection sites are shown in Additional file 2: Table S2. No significant difference in prevalence was observed among the four years of collection regardless of the considered site.
The prevalence (2.18\%) of B. miyamotoi found in Alsace among $I$. ricinus nymphs is consistent with the findings of other studies conducted in regions near Alsace $[16,17]$ and elsewhere in the Northern hemisphere [2, 25-27], as well as in regions where BMD is regularly described [2]. Collection site B showed a higher B. miyamotoi infection rate in $I$. ricinus nymphs; since $B$. burgdorferi (s.l.) was also found to have a higher prevalence at this collection site $[13,19]$, this result is in line with previous studies showing a correlation between infection rates of $B$. miyamotoi and B. burgdorferi (s.l.) in Ixodes ticks [28].

Interestingly, the prevalence of B. miyamotoi $(2.18 \%)$ among ticks in Alsace is close to the prevalence rates of A. phagocytophilum in this area (ranging from $0.4 \%$ to 1.2\%) [13]. This latter microorganism causes a similar febrile syndrome and is mainly diagnosed using molecular tools [20].

\section{Borrelia miyamotoi in febrile patients after a tick bite Patients}

Whole blood samples of 575 patients were sent to our laboratory for the detection of A. phagocytophilum by PCR; clinical data were available for 155 patients. Among these 155 patients, 89 remembered a tick bite, 131 had fever at the time of sampling, and the other patients had at least one other symptom occurring after a tick bite: articular pain, meningeal signs and headache. One hundred and one patients had hepatic or haematological abnormalities on the routine laboratory tests.

\section{Whole blood PCR}

None of the 575 whole blood samples were found to be positive by pan-RF Borrelia PCR. Consequently, no confirmed clinical cases of BMD could be evidenced by PCR methods in our cohort. This fact is corroborated by largescale studies on post-tick bite febrile illnesses. Indeed, a very small proportion of the tested blood samples were found to be PCR-positive for B. miyamotoi in these previous studies with rates of $0.16 \%(1 / 626), 0.84 \%(97 / 11,515)$, $0.33 \%$ (7/2150), $0.11 \%(8 / 7292)$ and $0.49 \%(2 / 408)$ [3, 4 , 10, 29, 30]. In contrast, in Russia, 15.2\% (46/302) of the post tick-bite febrile patients [2] were found PCR-positive for B. miyamotoi. In the Russian study [2] blood samples were all collected during febrile episodes which is consistent with recent observations demonstrating that B. miyamotoi spirochetemia only occurs during febrile episodes [31]. Moreover, Molloy et al. [3] have shown that spirochetemia is lower during $B$. miyamotoi infection (7787 spirochetes $/ \mathrm{ml}$ ) than during other RF Borrelia which can reach up to 100,000 spirochetes/ml [32]. Consequently, sampling during febrile episodes is important since it maximizes the likelihood of having PCR positive proven infection. Because not all acute samples were 
drawn during febrile episodes (median time of sampling after the onset of fever: 6 days (IQR: 4-12)), this is a limitation of the present study.

\section{Serological study}

All serum samples were tested to assess their IgM and IgG reactivity against B. miyamotoi GlpQ with ELISAs. The median time of sampling after the onset of fever was 6 days (IQR: 4-12) for acute samples. Convalescence samples were collected at a median of 6.28 weeks (IQR: 5.96-7.04) after the acute serum.

In total, 14/138 patients had at least one positive parameter (i.e. anti-GlpQ IgG and/or IgM) using the two-tiered algorithm (Table 1).

Patient A seroconverted between the acute and the late serum sampling in IgG and IgM. According to our definitions, exposure to $B$. miyamotoi can be considered as probable. However, this patient was found to be PCRpositive for A. phagocytophilum in the acute blood sample. Several hypotheses can explain these results. First, co-infection by $A$. phagocytophilum and $B$. miyamotoi could have occurred; although these are two rare tickborne microorganisms, some I. ricinus ticks were found to be positive for these two microorganisms [33]. Moreover, the acute serum was sampled 17 days after the disease onset and did not show a trace of anti-GlpQ IgM. Successive exposure to A. phagocytophilum and B. miyamoto $i$ is more likely to explain these results, especially as convalescence serum for $B$. miyamotoi was sampled nine weeks after the disease onset and because this person very often visited the forest. This seroconversion cannot be directly linked to a disease.

Patient B was found to have malaria because Plasmodium falciparum trophozoites were found in his blood smear, and a specific PCR assay for P. falciparum was positive in the acute sample. He was a soldier returning from a mission in an African country; since his return, he had regularly run in a forest in Alsace. Cross-reactivity leading to false positivity could explain these serological results. However, it should be mentioned that he could have had a possible contact with a RF Borrelia in Africa or with B. miyamotoi which could have given a positive anti-GlpQ IgM result in the acute serum without IgG seroconversion since he had been treated with doxycycline.

Patients C and D were found to have HGA; indeed, A. phagocytophilum PCR was positive in the acute sample. Very interestingly, they received doxycycline after the sampling of their acute sera. Doxycycline can prevent seroconversion in Lyme borreliosis [24] and could also have prevented the appearance of anti-GlpQ IgG in these patients. Here, again, serology evidenced a possible exposure to $B$. miyamotoi, but cross-reactivity leading to false positivity cannot be ruled out in these three patients. For patient J, the presence of isolated IgM without IgG seroconversion must be interpreted with caution; no clinical data could be collected concerning this case, which makes interpretation difficult.

Among the other ten patients out of the subset of 138 , cross-reactivity is highly probable for patients L and $M$ who had isolated IgM in their acute sera similar to patient $\mathrm{K}$ who had persistent anti-GlpQ IgM. Indeed, patient $\mathrm{L}$ had a serological profile compatible with a primary EBV infection. Patient $M$ had a positive PCR result for both EBV and CMV in the whole blood and CMV-positive PCR bronchoalveolar lavage fluid, and his clinical state was improved with foscarnet. The antibody response to these two viruses (EBV and CMV) is known to give false-positive results in serology, and these two agents more likely to explain the patient's symptoms. For patient $\mathrm{K}$, the diagnosis of a CMV infection was retained.

For patients G, H and I who had isolated IgM in their convalescence sera, the results are difficult to interpret and can hardly be linked to the acute event of fever since the convalescence sera were sampled about two months after the acute sera. Indeed, anti-GlpQ IgM reaches a peak approximately 11 and 20 days after disease onset, and anti-GlpQ IgG peaks between 21 and 50 days after the onset [22]. Cross-reactivity can explain these symptoms, but possible exposure to B. miyamoto $i$ without disease could also be considered as the patients' clinical state was good during the sampling of the late sera.

Interestingly, the acute serum of patients $\mathrm{E}$ and $\mathrm{N}$ was taken only four and five days respectively, after the disease onset. Within four days, the IgM response might not have fully developed, and thus could have only been detected during the convalescence blood sampling.

Finally, persistent IgG were observed in patient $\mathrm{F}$ indicating that he was probably previously exposed to B. miyamotoi.

The serological evidence provided by our study does not allow us to establish with certainty that the febrile syndromes are linked to B. miyamotoi infection as PCR would allow. However, collectively these results suggested possible exposure to B. miyamotoi in this cohort of patients as it has already been reported in the Netherlands [11], indicating that BMD could have been involved in the reported febrile episodes in some of these patients.

\section{Conclusions}

In this study we analyzed samples from 575 post-tick bite febrile patients and $4354 \mathrm{I}$. ricinus nymphs. We were able to detect $B$. miyamotoi in ticks collected 


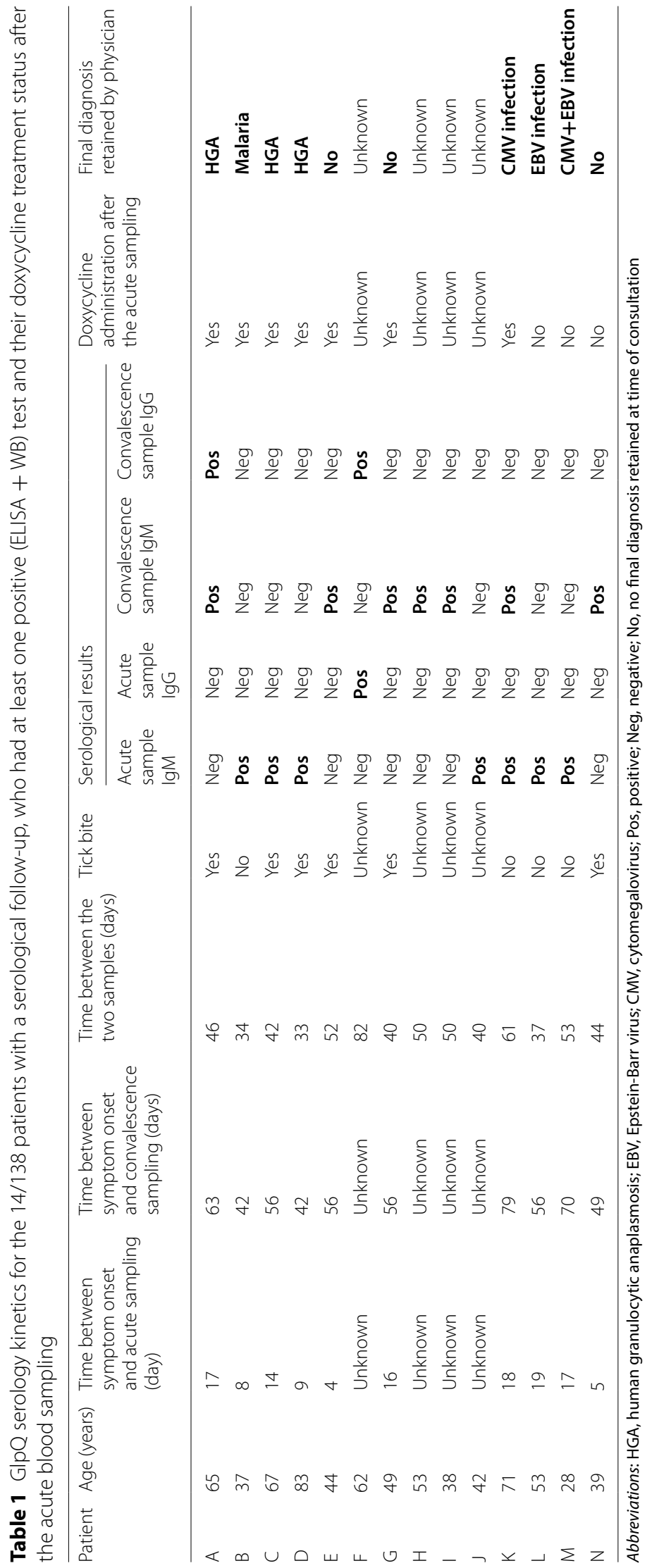


in the Alsace region (France) with an infection rate (2.18\%) consistent with tick infection rates in endemic regions of BMD in Russia and other areas in Europe. We were unable to detect $B$. miyamotoi by PCR in a cohort of 575 patients with fever after a tick bite. However, GlpQ serology suggested a possible B. miyamotoi exposure or acute infection in 14 of 138 patients.

\section{Supplementary information}

Supplementary information accompanies this paper at https://doi. org/10.1186/s13071-020-04071-9.

Additional file 1: Table S1. Multivariate analysis of B. miyamotoi prevalence among the four collection sites in Alsace and their GPS coordinates. Results are expressed using the odds ratio and its 95\% confidence interval $(95 \% \mathrm{Cl})$.

Additional file 2: Table S2. Proportion and number ( $n$ ) of B. miyamotoi infected nymphs and its 95\% confidence interval (95\% Cl), among the collected nymphs $(\mathrm{N})$ at the four sites during the four years of collection.

\section{Abbreviations}

BMD: Borrelia miyamotoi disease; CMV: Cytomegalovirus; DNA: deoxyribonucleic acid; EBV: Epstein-Barr virus; EDTA: ethylenediaminetetraacetic acid; GIpQ: glycerophosphodiester phosphodiesterase; HGA: human granulocytic anaplasmosis; PCR: polymerase chain reaction; rDNA: ribosomal DNA; RF: relapsing fever.

\section{Acknowledgements}

We thank the NRC for Borrelia staff for technical help in collecting ticks. We also thank Pierre Kieffer, Martin Martinot, Elisabeth Wurtz, Régis Dukic, Geneviève Boess, André Michel, Christophe Strady, Jean François Sagez, Nicolas Lefebvre and Xavier Argemi for their help in providing clinical data. Finally, we warmly thank Marie-Christine Michellet for the critical reading and English editing of the manuscript.

\section{Authors' contributions}

PHB wrote the manuscript, analyzed the data, performed PCR on patients and serology, collected ticks. JK corrected the manuscript, analyzed the serological data, performed serology. LZ collected ticks, performed PCR on patients and ticks. HS corrected the manuscript and performed the confirmatory test on the ticks. SJdM collected clinical samples and data. YH collected clinical samples and data. NB conceptualized the work, corrected the manuscript, supervised PHB and collected ticks. JWH conceptualized the work, corrected the manuscript, supervised JK. BJ conceptualized, supervised this study and corrected the manuscript. All authors read and approved the final manuscript.

\section{Funding}

Funding for this study was partly provided by the Programme Hospitalier de Recherche Clinique (PHRC) National No 3960 and partly by the French National Reference Center for Borrelia.

JWH \& HS were funded by ZonMW (project number 50-52200-98-313, 'Ticking on Pandora's box').

\section{Availability of data and materials}

All relevant data are included in the manuscript. Ten B. miyamotoi 165 rDNA sequences were deposited in the GenBank database under the accession numbers MN695028-MN695037.

\section{Ethics approval and consent to participate}

For patients for whom clinical data were collected, the work was approved by the European Clinical Trials Database (No EUDRACT: 2009 A00869-48). For the other patients, written information was given and non-opposition consent was obtained. The blood and serum samples were stored in a biobank no. DC-2009-1002.

\section{Consent for publication}

All the subjects for whom the clinical data were published completed a written informed consent.

\section{Competing interests}

The authors declare that they have no competing interests related to this study.

\begin{abstract}
Author details
${ }^{1}$ University of Strasbourg, Virulence bactérienne précoce UR7290-Lyme borreliosis group, FMTS - CHRU Strasbourg, Institut de Bactériologie, Strasbourg, France. ${ }^{2}$ Center for Experimental and Molecular Medicine, Academic Medical Center, University of Amsterdam, 1105 AZ Amsterdam, The Netherlands.

${ }^{3}$ French National Reference Center for Borrelia, Hôpitaux Universitaires de Strasbourg, Strasbourg, France. ${ }^{4}$ Centre for Zoonoses \& Environmental Microbiology, Centre for Infectious Disease Control, National Institute for Public Health and the Environment, Bilthoven, The Netherlands. ${ }^{5}$ Department of Infectious and Tropical Diseases, Hôpitaux Universitaires de Strasbourg, Strasbourg, France.
\end{abstract}

Received: 19 November 2019 Accepted: 9 April 2020

Published online: 17 April 2020

\section{References}

1. Krause PJ, Fish D, Narasimhan S, Barbour AG. Borrelia miyamotoi infection in nature and in humans. Clin Microbiol Infect. 2015;21:631-9.

2. Platonov AE, Karan LS, Kolyasnikova NM, Makhneva NA, Toporkova MG, Maleev W, et al. Humans infected with relapsing fever spirochete Borrelia miyamotoi, Russia. Emerg Infect Dis. 2011;17:1816-23.

3. Molloy PJ, Telford SR, Chowdri HR, Lepore TJ, Gugliotta JL, Weeks KE, et al. Borrelia miyamotoi disease in the Northeastern United States: a case series. Ann Intern Med. 2015;163:91-8.

4. Jobe DA, Lovrich SD, Oldenburg DG, Kowalski TJ, Callister SM. Borrelia miyamotoi infection in patients from upper midwestern United States, 2014-2015. Emerg Infect Dis. 2016;22:1471-3.

5. Chowdri HR, Gugliotta JL, Berardi VP, Goethert HK, Molloy PJ, Sterling SL, et al. Borrelia miyamotoi infection presenting as human granulocytic anaplasmosis: a case report. Ann Intern Med. 2013;159:21-7.

6. Hovius JWR, de Wever B, Sohne M, Brouwer MC, Coumou J, Wagemakers $A$, et al. A case of meningoencephalitis by the relapsing fever spirochaete Borrelia miyamotoi in Europe. Lancet. 2013;382:658.

7. Gugliotta JL, Goethert HK, Berardi VP, Telford SR. Meningoencephalitis from Borrelia miyamotoi in an immunocompromised patient. N Engl J Med. 2013:368:240-5.

8. Boden K, Lobenstein S, Hermann B, Margos G, Fingerle V. Borrelia miyamotoiassociated neuroborreliosis in immunocompromised person. Emerg Infect Dis. 2016:22:1617-20.

9. Henningsson AJ, Asgeirsson H, Hammas B, Karlsson E, Parke Å, Hoornstra D, et al. Two cases of Borrelia miyamotoi Meningitis, Sweden, 2018. Emerg Infect Dis. 2019;25:1965-8.

10. Jahfari S, Hofhuis A, Fonville M, van der Giessen J, van Pelt W, Sprong H. Molecular detection of tick-borne pathogens in humans with tick bites and erythema migrans, in the Netherlands. PLoS Negl Trop Dis. 2016;10:e0005042.

11. Jahfari S, Herremans T, Platonov AE, Kuiper H, Karan LS, Vasilieva O, et al. High seroprevalence of Borrelia miyamotoi antibodies in forestry workers and individuals suspected of human granulocytic anaplasmosis in the Netherlands. New Microbes New Infect. 2014;2:144-9.

12. Hoornstra D, Koetsveld J, Sprong H, Platonov AE, Hovius JW. Borrelia miyamotoi disease in an immunocompetent patient, western Europe. Emerg Infect Dis. 2018;24:1770-2.

13. Ferquel E, Garnier M, Marie J, Bernede-Bauduin C, Baranton G, Perez-Eid C, et al. Prevalence of Borrelia burgdorferi sensu lato and Anaplasmataceae members in Ixodes ricinus ticks in Alsace, a focus of Lyme borreliosis endemicity in France. Appl Environ Microbiol. 2006;72:3074-8.

14. Septfons A, Goronflot T, Jaulhac B, Roussel V, Martino SD, Guerreiro S, et al. Epidemiology of Lyme borreliosis through two surveillance systems: the national Sentinelles GP network and the national hospital discharge database, France, 2005 to 2016. Euro Surveill. 2019;24:1800134. 
15. Vandenesch A, Turbelin C, Couturier E, Arena C, Jaulhac B, Ferquel E, et al. Incidence and hospitalisation rates of Lyme borreliosis, France, 2004 to 2012. Euro Surveill. 2014;19:20883.

16. Moutailler S, Valiente Moro C, Vaumourin E, Michelet L, Tran FH, Devillers E, et al. Co-infection of ticks: the rule rather than the exception. PLOS Negl Trop Dis. 2016;10:e0004539.

17. Cosson J-F, Michelet L, Chotte J, Le Naour E, Cote M, Devillers E, et al. Genetic characterization of the human relapsing fever spirochete Borrelia miyamotoi in vectors and animal reservoirs of Lyme disease spirochetes in France. Parasit Vectors. 2014;7:233.

18. Michelet L, Joncour G, Devillers E, Torina A, Vayssier-Taussat M, Bonnet $\mathrm{Sl}$, et al. Tick species, tick-borne pathogens and symbionts in an insular environment off the coast of western France. Ticks Tick-Borne Dis. 2016:7:1109-15.

19. Goldstein V, Boulanger N, Schwartz D, George J-C, Ertlen D, Zilliox L, et al Factors responsible for Ixodes ricinus nymph abundance: are soil features indicators of tick abundance in a French region where Lyme borreliosis is endemic? Ticks Tick Borne Dis. 2018:9:938-44.

20. Hansmann Y, Jaulhac B, Kieffer P, Martinot M, Wurtz E, Dukic R, et al. Value of PCR, serology, and blood smears for human granulocytic anaplasmosis diagnosis, France. Emerg Infect Dis. 2019;25:996-8.

21. Flandrois J-P, Perrière G, Gouy M. leBIBIQBPP: a set of databases and a webtool for automatic phylogenetic analysis of prokaryotic sequences. BMC Bioinformatics. 2015;16:251.

22. Koetsveld J, Kolyasnikova NM, Wagemakers A, Stukolova OA, Hoornstra D, Sarksyan DS, et al. Serodiagnosis of Borrelia miyamotoi disease by measuring antibodies against GlpQ and variable major proteins. Clin Microbiol Infect. 2018;24:1338.e1-7.

23. Wagemakers A, Koetsveld J, Narasimhan S, Wickel M, Deponte K, Bleijlevens $B$, et al. Variable major proteins as targets for specific antibodies against Borrelia miyamotoi. J Immunol. 2016;196:4185-95.

24. Wormser GP, Dattwyler RJ, Shapiro ED, Halperin JJ, Steere AC, Klempner MS, et al. The clinical assessment, treatment, and prevention of lyme disease, human granulocytic anaplasmosis, and babesiosis: clinical practice guidelines by the Infectious Diseases Society of America. Clin Infect Dis. 2006:43:1089-134.

25. Subramanian G, Sekeyova Z, Raoult D, Mediannikov O. Multiple tickassociated bacteria in Ixodes ricinus from Slovakia. Ticks Tick Borne Dis. 2012;3:406-10

26. Crowder CD, Carolan HE, Rounds MA, Honig V, Mothes B, Haag H, et al. Prevalence of Borrelia miyamotoi in /xodes ticks in Europe and the United States. Emerg Infect Dis. 2014;20:1678-82.

27. Oechslin CP, Heutschi D, Lenz N, Tischhauser W, Péter O, Rais O, et al. Prevalence of tick-borne pathogens in questing /xodes ricinus ticks in urban and suburban areas of Switzerland. Parasit Vectors. 2017;10:558.

28. Wagemakers A, Staarink PJ, Sprong H, Hovius JWR. Borrelia miyamotoi: a widespread tick-borne relapsing fever spirochete. Trends Parasitol. 2015;31:260-9.

29. Kingry LC, Anacker M, Pritt B, Bjork J, Respicio-Kingry L, Liu G, et al. Surveillance for and discovery of Borrelia species in US patients suspected of tickborne illness. Clin Infect Dis. 2018;66:1864-71.

30. Sato K, Takano A, Konnai S, Nakao M, Ito T, Koyama K, et al. Human infections with Borrelia miyamotoi, Japan. Emerg Infect Dis. 2014;20:1391-3.

31. Karan L, Makenov M, Kolyasnikova N, Stukolova O, Toporkova M, Olenkova O. Dynamics of spirochetemia and early PCR detection of Borrelia miyamotoi. Emerg Infect Dis. 2018;24:860-7.

32. Horton JM. Relapsing fever caused by Borrelia species. In: Bennett JE, Dolin $\mathrm{R}$, Blaser $\mathrm{M}$, editors. Principles and practice of infectious diseases. Philadelphia: Elsevier Sauders; 2015. p. 2721-4.

33. Takumi K, Sprong H, Hofmeester TR. Impact of vertebrate communities on Ixodes ricinus-borne disease risk in forest areas. Parasit Vectors. 2019:12:434

\section{Publisher's Note}

Springer Nature remains neutral with regard to jurisdictional claims in published maps and institutional affiliations.
Ready to submit your research? Choose BMC and benefit from:

- fast, convenient online submission

- thorough peer review by experienced researchers in your field

- rapid publication on acceptance

- support for research data, including large and complex data types

- gold Open Access which fosters wider collaboration and increased citations

- maximum visibility for your research: over $100 \mathrm{M}$ website views per year

At BMC, research is always in progress.

Learn more biomedcentral.com/submissions 